\title{
Extranodal Diffuse Non Hodgkin Lymphoma in the Thigh
}

\author{
E. Bölke ${ }^{1}$, M. Peiper ${ }^{2}$, C. Matuschek ${ }^{1}$, G. Schieren ${ }^{3}$, R. Glombick 5 , C. Förster 6 , \\ W. Budach ${ }^{1}, \mathrm{~K}$. Orth ${ }^{4}$
}

\begin{abstract}
${ }^{1}$ Department of Radiation Therapy and Radiation Oncology, University of Düsseldorf, ${ }^{2}$ Department of Surgery, University of Düsseldorf, ${ }^{3}$ Department of Nephrology, University of Düsseldorf, ${ }^{4}$ Department of Surgery, KRH Hannover, ${ }^{5}$ Department of Radiology, University of Düsseldorf, ${ }^{6}$ Department of Pathology, KRK Hannover, Germany
\end{abstract}

\begin{abstract}
Diffuse large B-cell lymphoma usually starts as a rapidly growing mass in an internal lymph node and can grow in other areas such as the bone or intestines. About $1 / 3$ of these lymphomas are confined to one part of the body when they are localized. In the case of a 78-year-old man, an extensive tumour was located on the right thigh. Biopsies of the tumour revealed diffuse proliferation of large lymphoid cells which have totally affected the normal architecture of striated muscle. The patient received multimodality treatment including chemotherapy of the CHOP regimen and adjuvant radiotherapy. Despite this being a fast growing lymphoma, about 3 out of 4 people will have no signs of disease after initial treatment, and about half of all people with this lymphoma are cured with therapy.
\end{abstract}

\section{CASE RePort}

A 78-year-old man presented to our hospital with an extensive tumor located on the right thigh (Fig. A-B).
The patient reported that he had been treating the fast growing tumor with complementary medicine for 6 weeks prior to consulting our hospital. Histopathological examination of a biopsy revealed diffuse proliferation of large lymphoid cells which have totally affected the normal architecture of striated muscle (Fig. C-D). The medium- to large sized neoplastic cells expressed pan B-cell markers such as CD 20 corresponding to an extra nodal diffuse large B-cell lymphoma.

Further screening diagnostics revealed an uni-localized tumour restricted to the right thigh. Our patient received multimodality treatment including chemotherapy of the CHOP scheme and adjuvant radiotherapy.

Diffuse large B-cell lymphoma (DLBCL) can affect any age group but occurs mostly in older people. It usually starts as a quickly growing mass in an internal or superficial lymph node and can infiltrate other areas such as the intestine, bone, or even the brain or spinal cord. About 1 out of 3 of these lymphomas is confined to one part of the body when it is found. Localized lymphomas are easier to treat than when they have
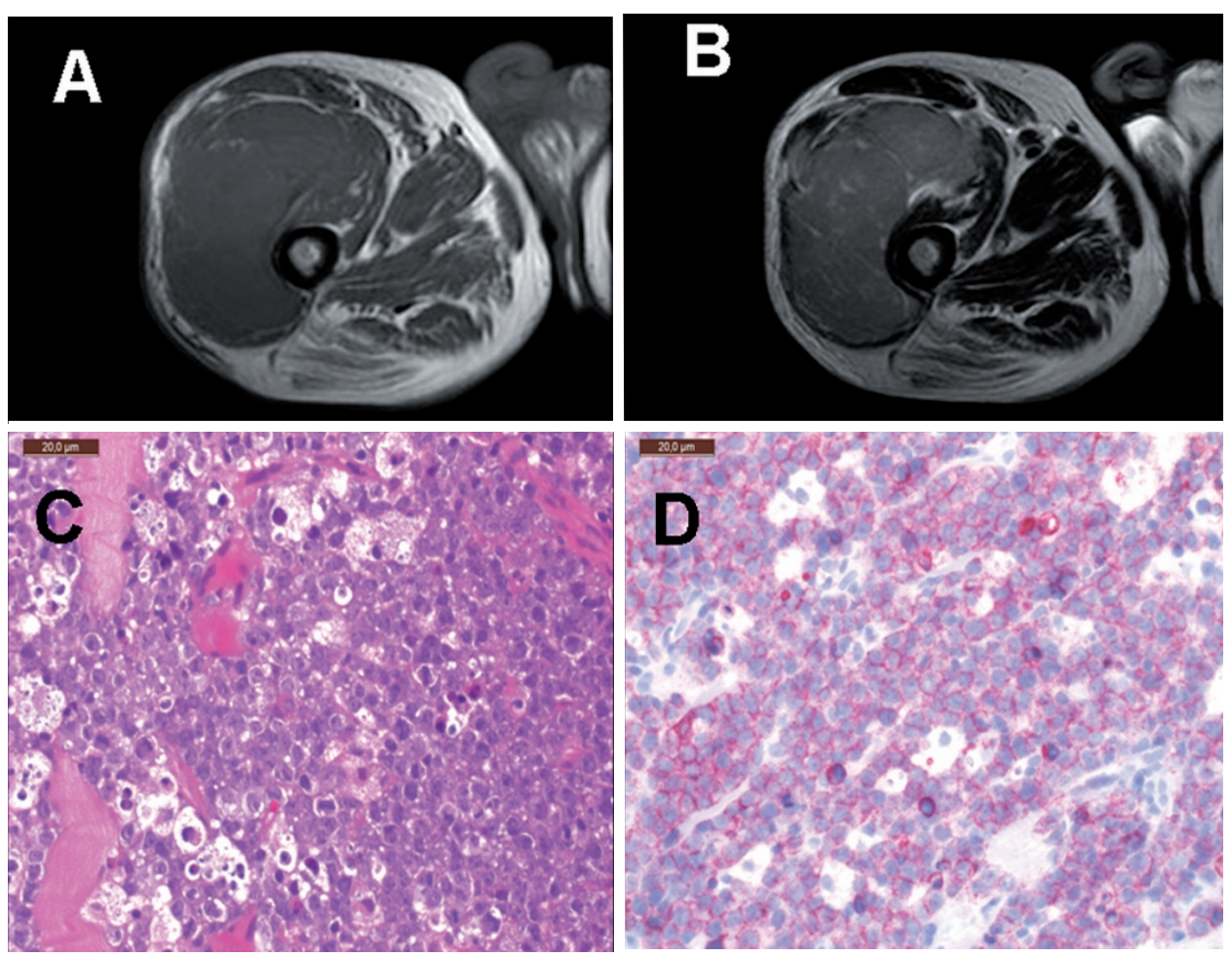

Fig. A, B: MRT of the right thigh, transversal scan $\mathrm{T} 1$ and $\mathrm{T} 2$ respectively.

Fig. C: HE-staining of a diffuse proliferation of large lymphoid cells which have totally affected the normal architecture of striated muscle.

Fig. D: The neoplastic cells express pan-B-cell markers such as CD 20. 
spread to other parts of the body. There are different genetic subtypes of DLBCL, even though they look the same under the microscope. These subtypes seem to have different prognoses and responses to treatment. This is a fast growing lymphoma, but it often responds well to treatment with radio-chemotherapy. Overall, about 3 out of 4 people will have no signs of disease after initial treatment, and about half of all people with this lymphoma are cured with therapy [1-4].

This work is dedicated to Roland Radner

\section{LITERATURE}

1. Caimi PF, Barr PM, Berger NA, Lazarus HM. Caimi PF, Barr PM, Berger NA, Lazarus HM. Non-Hodgkin's lymphoma in the elderly. Drugs Aging. 2010 Mar 1; 27(3): 211-38

2. Gutiérrez A, Mestre F, Pérez-Manga G, Rodríguez J. Diffuse large B-cell lymphoma in the older. Crit Rev Oncol Hematol. 2010 Mar 18. [Epub ahead of print]

3. Mannina D, Luminari S, Dondi A, Polimeno G, Baldini L, Stelitano C, Merli F, Dell'Olio M, Gobbi PG, Giglio G, Barbolini E, Brugiatelli M, Federico M. Long term outcome of patients with localized aggressive non-Hodgkin lymphoma treated with PROMECE-CYTABOM plus involved-field radiation therapy: a study by the Gruppo Italiano Studio Linfomi. Leuk Lymphoma. 2010 Mar; 51(3):422-9.
4. Mocikova H: Prognostic significance of absolute lymphocyte count and lymphocyte subsets in lymphomas. Prague Med Rep. 2010;111(1):5-11.

Received: April 9, 2010 / Accepted: June 16, 2010

Address for correspondence:

PD. Dr. med. Edwin Bölke

Klinik für Strahlentherapie und Radiologische Onkologie

Heinrich-Heine-Universität Düsseldorf

Moorenstraße 5

40225 Düsseldorf

Germany

Phone: +49-211-8117990

Fax: +49-211-81118051

Email: boelke@med.uni-duesseldorf.de 